\title{
ANÁLISE DE CENÁRIO ENVOLVENDO EMBALAGENS VAZIAS DE AGROTÓXICOS ORIGINADAS DA CULTURA DA MACIEIRA
}

VALÉRIA NOGUEIRA DE SOUZA*

LUCIANO GEBLER**

\begin{abstract}
Utilizam-se agrotóxicos em diversas fases do ciclo produtivo da macieira, gerando embalagens vazias a recolher conforme a legislação brasileira. Este trabalho teve como objetivo identificar os materiais componentes das embalagens devolvidas por agricultores dedicados exclusivamente à cultura da macieira, analisar sua distribuição anual na unidade de recebimento de Vacaria (RS) e verificar a existência de relação entre as entradas por tipo de material e as fases fenológicas da macieira, durante o período de 2007 a 2010. Das embalagens recebidas, em média, ao longo dos anos agrícolas, 39,8 \% eram plásticas rígidas; 36,8 \% de papelão; 15,7 \% flexíveis não laváveis; 7,5 \% metálicas rígidas; e, 0,2 \% de vidro, com picos de recebimento em julho e dezembro para embalagens flexíveis não laváveis. Não foi verificada relação com as fases fenológicas da planta, mas sim com os ciclos fisiológicos da cultura. Quanto à disposição final, é importante para as unidades de recebimento maximizar o volume de embalagens lavadas de plástico rígido e reduzir o volume de embalagens flexíveis não lavadas até serem criadas opções de reutilização econômica para essa última, além da incineração.
\end{abstract}

PALAVRAS-CHAVE: UNIDADES DE RECEBIMENTO DE EMBALAGEM; AGROTÓXICOS; MALEICULTURA.

* Engenheira Agrônoma, MSc. em Zootecnia, Autônoma, Vacaria, RS, Brasil (e-mail: valernog@hotmail. com).

** Engenheiro Agrônomo, Doutor em Recursos Hídricos e Saneamento Ambiental, Pesquisador, Embrapa Uva e Vinho, Professor, Universidade de Caxias do Sul (CAMVA), Vacaria, RS, Brasil (e-mail: luciano. gebler@ embrapa.br). 


\section{INTRODUÇÃO}

O município de Vacaria (RS), com área de aproximadamente 6.900 hectares, detém, respectivamente, a metade da área destinada à maleicultura no estado do Rio Grande do Sul e $20 \%$ da brasileira, tendo sido responsável por 52 \% da produção gaúcha (AGAPOMI, 2011; PMV, 2011).

Na região de Vacaria, na safra 2009/2010, Fioravanço et al. (2010) relacionaram os principais estádios fenológicos da macieira com seus respectivos períodos de ocorrência (Figura 1).

$\mathrm{Na}$ macieira, como na maioria das culturas comerciais, a proteção fitossanitária dos pomares ocorre de forma integrada com diferentes métodos, porém em diversas fases de seu ciclo produtivo, a aplicação de agrotóxicos ainda é a responsável pela produtividade aliada à qualidade esperada do sistema (LIMA et al., 2009).

$\mathrm{Na}$ base de dados do Sistema de Agrotóxicos Fitossanitários (AGROFIT), desenvolvida pelo Ministério de Agricultura, Pecuária e Abastecimento, os produtos registrados para a cultura da macieira são distribuídos em nove classes de uso, 50 grupos químicos e 85 ingredientes ativos. O maior número de produtos formulados constitui-se por fungicidas (35\%) e inseticidas (23\%), seguidos pelos acaricidas (19 \%) e herbicidas (7\%). Essa distribuição condiz com a literatura referente à fruticultura (BEDOR et al., 2009).

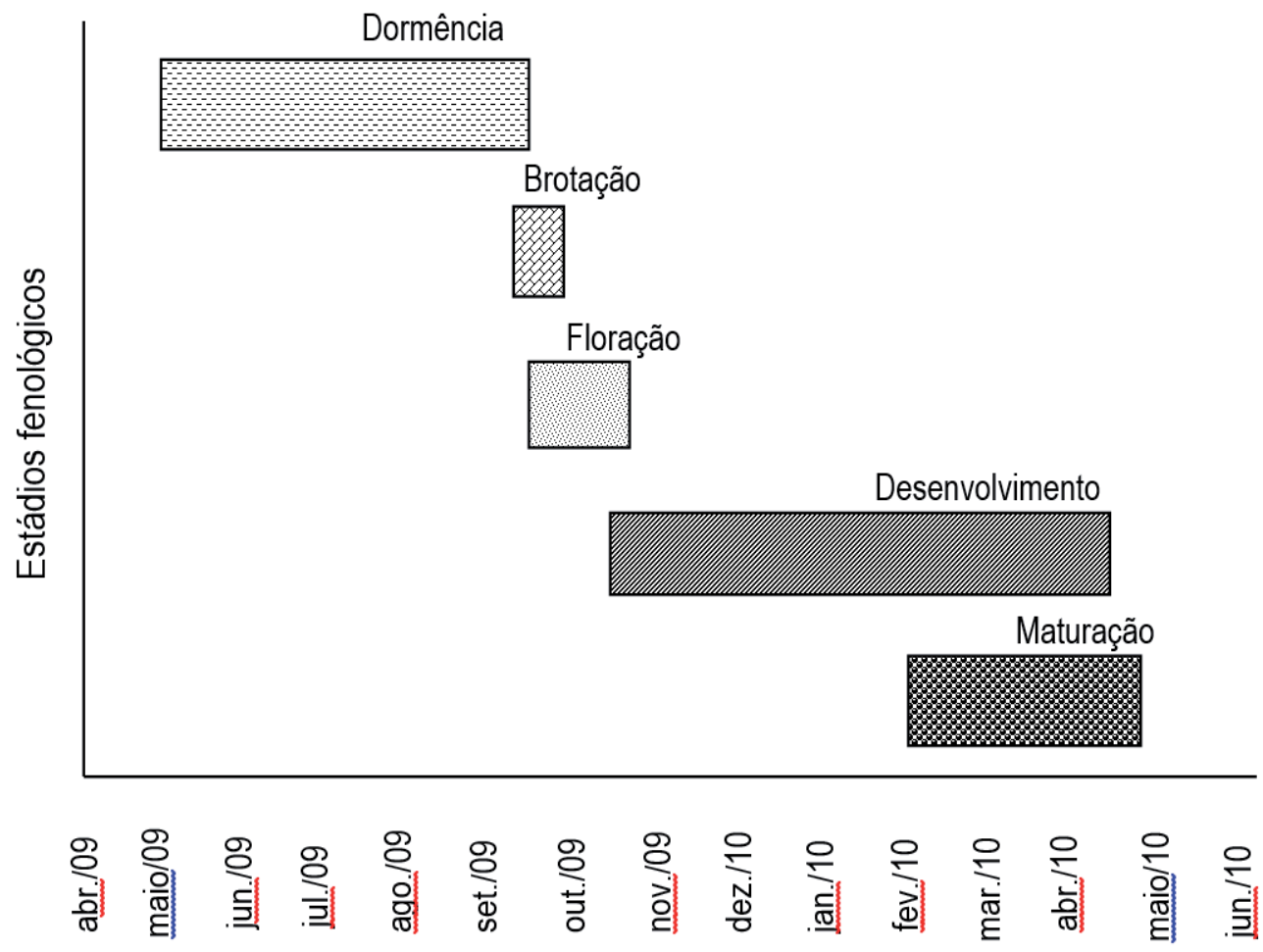

\section{FIGURA 1 - ESTÁDIOS FENOLÓGICOS DA MACIEIRA NA SAFRA 2009/2010 EM VACARIA (RS)}

Fonte: FIORAVANÇO et al. (2010).

De acordo com a Lei n. 12.305, resíduos agrossilvopastoris são aqueles gerados nas atividades agropecuárias e silviculturais, incluídos os relacionados a insumos nelas utilizados. No Brasil, a destinação final desses resíduos é regulamentada por legislação específica que assume como forma ambientalmente adequada de destinação final a reciclagem e a incineração controlada, desde que efetuadas por empresas licenciadas pelos órgãos ambientais competentes (BOLDRIN et al., 2007). 
Entre os principais fatores determinantes do destino final das embalagens vazias de agrotóxicos encontra-se o tipo de material que a constitui e sua periculosidade ao meio ambiente. Essa é determinada em função da possibilidade de realização do processo de tríplice lavagem no momento de preparo da calda, indicada pela Norma 10.004 da ABNT (2004), havendo duas classes de resíduos: I - perigosos; II - não perigosos.

Conforme Gerassi (2010), as embalagens vazias de agrotóxicos eram classificadas até 1997 como pertencentes à classe I (resíduos sólidos perigosos). Naquele ano, foi publicada a NBR 13.968 estabelecendo os procedimentos para a adequada lavagem de embalagens rígidas vazias de agrotóxicos, as quais passaram a ser classificadas como resíduo não perigoso (classe II) para fins de manuseio, transporte e armazenagem. Embalagens que acondicionam produtos na forma sólida (em grânulo ou pó), os destinados ao tratamento de sementes, ou cuja forma de aplicação exija volume ultra-baixo de água (menos de 20 litros por hectare) impedindo a tríplice lavagem, continuam pertencendo à classe $\mathrm{I}$.

Segundo o Instituto Nacional de Processamento de Embalagens Vazias (INPEV, 2011), embalagens de produtos miscíveis em água e aplicados com equipamentos de pulverização estão aptas à reciclagem quando submetidas pelo agricultor, no momento do preparo da calda, ao processo de tríplice lavagem. Geralmente são embalagens rígidas de plástico ou metal, ou embalagens secundárias que não tiveram contato direto com os produtos, como as caixas de papelão utilizadas para acondicionar frascos ou sacos de agrotóxicos. A incineração é o destino final das embalagens flexíveis (sacos) que se encaixam nas demais situações ou das embalagens que não foram corretamente lavadas pelo agricultor.

Para o INPEV (2011), 95 \% das embalagens vazias de agrotóxicos colocadas no mercado são passíveis de reciclagem, desde que seja obedecido o processo da tríplice lavagem. São incineradas as embalagens não laváveis ( $5 \%$ do total) e aquelas que não foram submetidas à tríplice lavagem pelos agricultores.

A logística reversa das embalagens vazias de agrotóxicos, além de ser dependente do uso adequado dos produtos pelos agricultores e da classificação dos resíduos nas unidades de recebimento como laváveis e não laváveis, sofrem influência do fluxo de entrada das embalagens nessas unidades (BOLDRIN et al., 2007).

Segundo a legislação, o agricultor tem o prazo de até um ano (a contar da data da compra do agrotóxico) para efetuar a devolução das embalagens vazias a uma unidade licenciada por órgão ambiental (BOLDRIN et al., 2007). Como o fluxo de entrada de embalagens nas unidades de recebimento depende das culturas predominantes em sua região de atuação, a composição das embalagens recebidas e a dinâmica das entradas na unidade podem ser influenciadas por determinada cultura ou seu estágio.

$\mathrm{Na}$ unidade de recebimento localizada no município de Vacaria (RS), em diversas épocas do ano, as entradas de embalagens vazias de agrotóxicos do sistema produtivo da maçã são predominantes em relação ao recebimento de embalagens oriundas de outras culturas. Isso se reflete na quantidade de embalagens que serão destinadas à incineração ou à reciclagem e interfere no orçamento da unidade de recebimento para a destinação final desses resíduos. Situação similar foi observada por BOLDRIN et al. (2007), justificando a replicação do seu estudo para o caso da maçã como forma de gerar cenários preditivos segundo seu desenvolvimento.

\section{MATERIAL E MÉTODOS}

Desenvolveu-se o estudo mediante cruzamento e análise de informações originárias dos bancos de dados cadastrais, bem como dos relatórios de entrada de embalagens vazias de agrotóxicos da Associação dos Revendedores de Agrotóxicos dos Campos de Cima da Serra, entidade que gerencia a Central de Recebimento de Embalagens Vazias de Agrotóxicos, localizada no município de Vacaria, Estado do Rio Grande do Sul (CENTRAL ..., 2011). 
O período analisado abrangeu de 2007 a 2010, tendo sido extraídas informações sobre quantidade (peso), tipos de materiais e datas de recebimento de embalagens vazias de agrotóxicos devolvidas pelos agricultores da Região dos Campos de Cima da Serra, no total de 469 agricultores ou empresas, de todas as culturas agrícolas presentes na região.

A cultura da macieira foi selecionada pela importância que representa na Região atendida pela Central de Vacaria e por ser considerada como geradora de grande volume de resíduos sólidos destinados à incineração.

De acordo com o cadastro foram identificados inicialmente 96 agricultores que, entre outras atividades, desenvolviam o cultivo de macieiras. Desses, foram selecionados 28 produtores (5,97 \% do total e $29,16 \%$ dos agricultores que cultivam maçãs) que apresentavam a maleicultura como atividade comercial exclusiva, com uma série temporal de dados no período.

Com os dados relativos às devoluções de embalagens vazias de agrotóxicos à Central de Vacaria, realizadas pelos agricultores selecionados, a fase seguinte foi ordenar e agrupar os dados segundo os tipos de embalagens e materiais constituintes e analisar os resultados.

\section{RESULTADOS}

Os resultados revelaram que no período de 2007 a 2010, em média, do peso de embalagens recebidas de maleicultores na Central de Vacaria, 39,8 \% eram embalagens plásticas rígidas (envases e tampas); 36,8 \% de papelão (caixas); 15,7 \%, embalagens flexíveis não laváveis (sacos); $7,5 \%$, metálicas rígidas; e 0,2 \% de vidro (Figura 2).

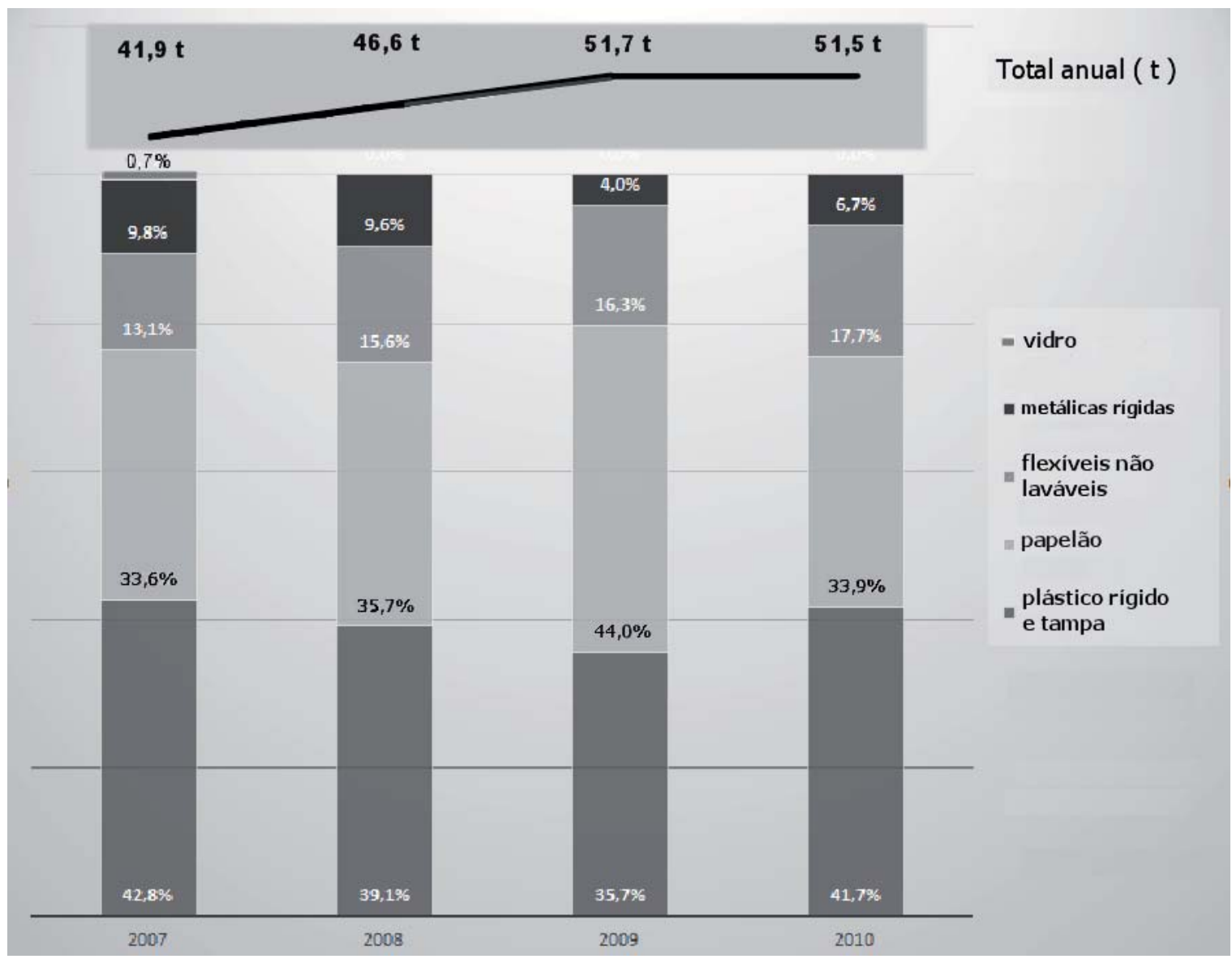

FIGURA 2 - PERCENTUAIS POR TIPO DE MATERIAL DAS EMBALAGENS VAZIAS DE AGROTÓXICOS DEVOLVIDAS POR MALEICULTORES À CENTRAL DE RECEBIMENTO DE VACARIA (RS) NOS ANOS DE 2007 A 2010 
É possível observar que a posição relativa dos materiais foi mantida nos anos de 2007, 2008 e 2010 em ordem decrescente: plástico rígido (envases e tampas), papelão (caixas), flexíveis não laváveis (sacos) e metal. Em 2009, o recebimento de embalagens de papelão (44 \%) superou o de embalagens de plástico rígido (36\%). Os demais materiais mantiveram as mesmas posições dos anos de 2007, 2008 e 2010, sugerindo que a indústria de agrotóxicos elegeu o plástico rígido como seu principal contentor de líquidos, mas utilizando papelão para o empacotamento de outros tipos de embalagens de agrotóxicos com materiais diversos.

O recebimento de embalagens constituídas por vidro vem evidenciando pouca variação, mas em declínio. Em 2007 apresentou o volume mais expressivo dentre os anos estudados, porém com recebimento ocasional e em quantidade ínfima ( $0,7 \%$ do total). Isto sugere que quando há devolução de embalagens de agrotóxicos constituídas por vidro, trata-se de material antigo armazenado nas propriedades agrícolas, indicando que ele é desconsiderado como opção para acondicionamento de agrotóxicos pelos fabricantes.

Os dados demonstraram que o peso total de embalagens vazias de agrotóxicos recebido passou de 41,9 para 51,5 toneladas, entre 2007 e 2010, representando aumento de $23 \%$ com incremento anual de 3,4 toneladas. Dados da AGAPOMI (2011) apontam que no período de 2006 a 2010 houve $45,4 \%$ de crescimento na produtividade dos pomares localizados em Vacaria, ampliando a produção local da fruta de 171 mil toneladas para aproximadamente 248 mil toneladas, com aumento de área cultivada pouco maior que 11 \% (Figura 3).

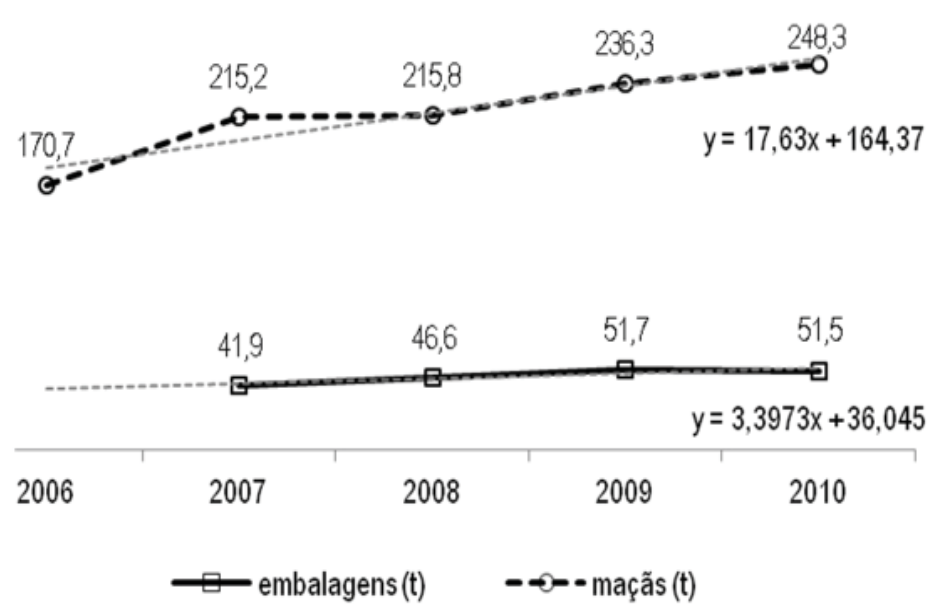

\section{FIGURA 3 - EVOLUÇÃO DOS PESOS, EM TONELADAS, DA PRODUÇÃO DE MAÇÃS EM VACARIA (RS) E DO TOTAL DE EMBALAGENS RECEBIDAS DE MALEICULTORES NA CENTRAL DE VACARIA NO PERÍODO DE 2006 A 2010}

Fonte: AGAPOMI (2011) e Central ... (2011).

Com base na representação gráfica da evolução da produção de maçãs, entre 2006 e 2010, e da evolução do recebimento de embalagens vazias de agrotóxicos efetuadas por maleicultores, durante o período de 2007 a 2010, pode-se afirmar que as inovações implantadas com sucesso por esses produtores foram auxiliadas pela utilização de agrotóxicos, comprovando o cenário exposto por Fioravanço et al. (2010).

As médias dos dados de recebimento de embalagens vazias de agrotóxicos no período de 2007 a 2010 mostram que a entrega ocorreu diversas vezes ao longo do ciclo da macieira, pouco tempo após o uso dos agrotóxicos. Em determinados meses, no entanto, são mais expressivas constituindo picos de recebimento (Figura 4).

As médias de recebimento de embalagens plásticas rígidas (envases e tampas), de papelão (caixas) e flexíveis não lavadas (sacos) apresentaram comportamentos semelhantes entre 
os meses de maio a setembro, com tendência de crescimento em maio, pico máximo em julho e menores níveis de recebimento entre agosto e setembro. A partir do início da fase vegetativa da macieira, em outubro, até o final da colheita no final de abril (Figura 1), as quantidades recebidas de todos os materiais devolvidos como embalagens vazias mantiveram-se bem acima dos registros realizados durante o período de repouso da planta, de maio até setembro (Figura 4). Tal fato fornece indícios de que esses produtos constituem instrumentos auxiliares a muitas das práticas culturais demandadas nas diferentes fases do período.

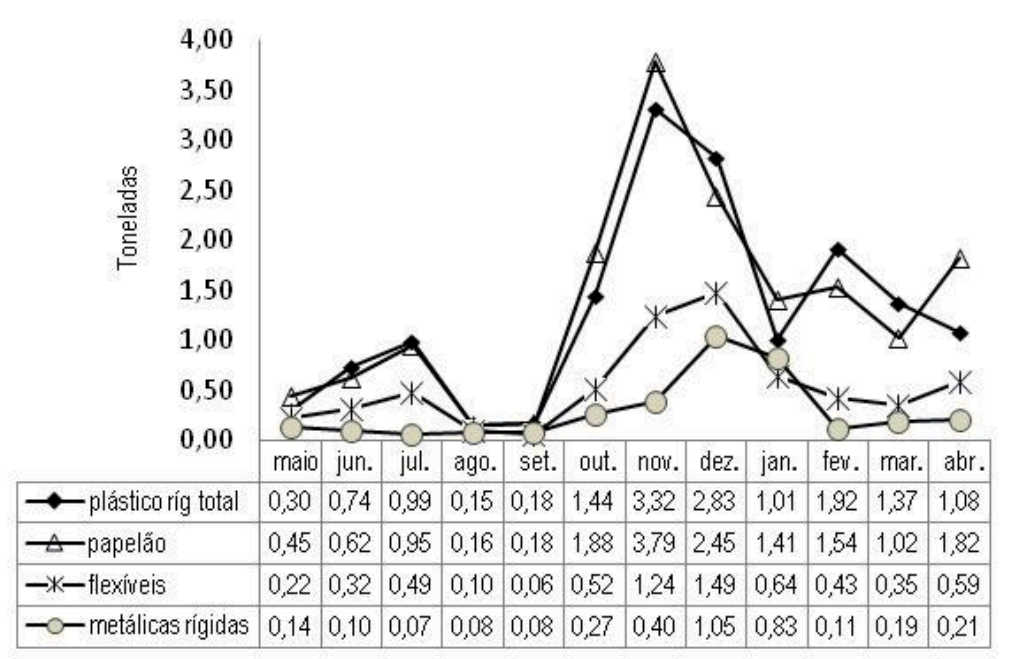

\section{FIGURA 4 - MÉDIAS DE PESO DE EMBALAGENS VAZIAS DE AGROTÓXICOS, EM TONELADAS, DEVOLVIDAS POR MALEICULTORES À CENTRAL DE VACARIA NO PERÍODO DE 2007 A 2010}

Os dados analisados não permitiram relacionar o comportamento dos recebimentos de embalagens às fases fenológicas da planta, mas revelaram estreito relacionamento com os dois ciclos fisiológicos da macieira - dormência e vegetativo.

A incineração é a opção para destinação de embalagens flexíveis não laváveis (sacos) e de embalagens laváveis não lavadas pelo agricultor, mas nos relatórios dos dados coletados não constavam informações sobre a adequação das embalagens laváveis ao cumprimento da exigência da tríplice lavagem. Assim, todas as embalagens rígidas foram consideradas devolvidas de acordo com a legislação em vigor (BOLDRIN et al., 2007) e, portanto, sem necessidade de serem destinadas à incineração.

Conforme os dados amostrados, as embalagens flexíveis não laváveis destacaramse na totalidade de materiais recebidos, tanto pela evolução das quantidades devolvidas pelos agricultores (de 5,5 toneladas, em 2007, para 9,1 toneladas em 2009), quanto pelo peso apresentado relativamente aos demais materiais em todos os anos do período de 2007 a 2010.

De acordo com estimativas do INPEV (2011), apenas $5 \%$ das embalagens vazias de agrotóxicos colocadas no mercado brasileiro devem ser incineradas. Já a devolução de embalagens flexíveis não laváveis à Central de Vacaria, realizada por agricultores dedicados exclusivamente à maleicultura, correspondeu a $15,7 \%$ do peso total de embalagens recebidas na média do período de 2007 a 2010, tendo sido observados picos de recebimento desse tipo de embalagem em julho $(490 \mathrm{~kg})$ e em dezembro $(1.490 \mathrm{~kg})$.

Para Lerina (2011), a relação de peso de embalagem gerada por litro de produto utilizado é de 0,065 kg para plástico rígido. Buscou-se obter essa relação para embalagens flexíveis na Central de Vacaria, efetuando a pesagem de 375 sacos de vários agrotóxicos utilizados em maçã, com diferentes volumes e compostos por diversos materiais flexíveis, chegando-se à 
relação $0,032 \mathrm{~kg}$ de embalagem flexível por litro/quilograma de produto utilizado. Com base na relação de peso de embalagem por volume de produto utilizado, cada 1.000 litros/quilogramas de agrotóxicos acondicionados em embalagens plásticas rígidas geram, em média, $65 \mathrm{~kg}$ de resíduo para reciclagem, enquanto que embalagens flexíveis geram, em média, $32 \mathrm{~kg}$ de resíduos para a incineração controlada. No caso da maçã, portanto, cada tonelada de embalagens flexíveis devolvida à unidade de recebimento resultou da utilização do dobro do volume de agrotóxicos em relação às embalagens plásticas rígidas.

Sob o aspecto de gestão, a menor geração de resíduo por unidade de volume de agrotóxico e a facilidade de prensagem e enfardamento nas unidades de recebimento geram aproveitamento mais eficiente de espaço nos caminhões em relação aos frascos, baldes, tambores e latas, resultando na otimização dos fretes. No entanto, no contexto do sistema de logística reversa de embalagens vazias de agrotóxicos em que a reciclagem é a fonte de recursos para a manutenção das atividades das unidades de recebimento, a incineração ainda representa custo ao sistema, sendo desejável a diminuição do seu recebimento.

Convém lembrar a percepção negativa da sociedade sobre o acondicionamento de agrotóxicos em embalagens flexíveis não laváveis, devido à necessidade de incineração dos resíduos (PINTO JUNIOR e BRAGA, 2009), mesmo que essa prática seja aprovada tecnicamente para garantir a eliminação de resíduos não detectados na separação entre embalagens lavadas ou contaminadas (CANTOS, MIRANDA e LICCO, 2008).

Enquanto não houver alternativa econômica de geração de renda mediante a incineração de embalagens flexíveis não laváveis, sua grande participação no volume final de embalagens devolvidas por maleicultores torna oneroso o funcionamento da central de agrotóxicos.

\section{CONCLUSÃo}

O estudo confirmou a existência de relação entre as épocas de recebimento de embalagens provenientes de maleicultores e as fases fisiológicas da macieira (estágios vegetativo e de dormência), mas não entre as fases fenológicas da cultura.

O percentual de recebimento de embalagens flexíveis, com destino à incineração na Central de Vacaria, na média do período de 2007 a 2010, foi três vezes maior que o estimado em nível nacional pelo INPEV, mostrando a influência das particularidades regionais no funcionamento do sistema de logística reversa de embalagens vazias de agrotóxicos.

Verificou-se a necessidade de substituição das embalagens flexíveis não laváveis utilizadas na cultura da macieira por outro tipo de embalagem reciclável por parte da indústria, ou a introdução de novas maneiras de gerar renda com esse resíduo de forma a reduzir o custo do processo de descarte final da unidade de recebimento e garantir a manutenção do sistema.

\section{ABSTRACT \\ SCENARIO ANALYSIS INVOLVING EMPTY CONTAINERS OF PESTICIDES FROM APPLE ORCHARDS}

Pesticides are used in several phases along the apple production cycle and generating empty containers that according to Brazilian law must be collected. The aim of this study was to characterize the material components of packages returned by apple growers; to analyze their annual distribution in the collection stationl of Vacaria (RS-Brazil) and verify a possible relation between the inputs by type of material and the phenological stages of apple tree between 2007 and 2010. Among packaging received during this period, $39.8 \%$ were made of rigid plastic; $36.8 \%$ cardboard, $15.7 \%$ non-washable flexible, $7.5 \%$ metallic rigid and, $0.2 \%$ for glass, distributed throughout the year with receipt peaks of flexible packaging in July and December. The periods in which the packages were received showed to be related to physiological cycles of culture instead of phenological phases of the plant. Regarding disposal, it is important for the unit to maximize the volume of washed rigid plastic packaging and reduce the volume of unwashed flexible packaging, until there are economic reuse options for his last beside incineration. 


\section{REFERÊNCIAS}

1 ABNT. Associação Brasileira de Normas Técnicas. NBR 10004: resíduos sólidos - classificação. São Paulo, 2004. 77 p.

2 AGAPOMI. Associação Gaúcha dos Produtores de Maçã. Dados estatísticos (2011). Disponível em: http://www.agapomi. com.br/dadosestatisticos.php. Acesso em: 08 jun. 2011.

3 BEDOR, C.N.G.; RAMOS, L.O.; PEREIRA, P.J.; RÊGO, M.A.V.; PAVÃO, A.C.; AUGUSTO, L.G.S. Vulnerabilidades e situações de risco relacionadas ao uso de agrotóxicos na fruticultura irrigada. Revista Brasileira de Epidemiologia, v.12, p.39-49, 2009.

4 BOLDRIN, V.P.; TREVISAN, E.F.; BARBIERI, J.C.; FEDICHINA, M.A.H.; BOLDRIN, M.S.T. A gestão ambiental e a logística reversa no processo de retorno de embalagens de agrotóxicos vazias. Revista da Administração e Inovação, v.4, p.29-48, 2007.

5 CANTOS, C.; MIRANDA, Z.A.I.; LICCO, E.A. Contribuições para a gestão das embalagens vazias de agrotóxicos. Revista de Gestão Integrada em Saúde do Trabalho e Meio Ambiente, v.3, p.1-36, 2008.

6 Central de Recebimento de Embalagens Vazias de Agrotóxicos de Vacaria. Relatório de recebimento de embalagens vazias de agrotóxicos no período de 2006 a 2010, gerado pelo Sistema de Informações de Centrais, SIC-inpEV. Vacaria, 2011.

7 FIORAVANÇO, J.C.; CZERMAINSKI, A.B.C.; ALVES, S.A.M.; NACHTIGALL, G.R. Condições meteorológicas e sua influência na safra de maçã 2009/10 na Região de Vacaria, RS. Bento Gonçalves: Embrapa Uva e Vinho, 2010. 8 p. (Comunicado Técnico, 100).

8 GERASSI, P.V.M. Manual de destinação final de embalagens vazias de produtos fitossanitários. Disponível em: http://www.bvsde.ops-oms.org/ muwww/fulltext/resipeli/destinac/destinac.html. Acesso em: 15 out. 2010.

9 Instituto Nacional de Processamento de Embalagens Vazias (INPEV). Estatística. Disponível em: http://www.inpev.org. br. Acesso em: 12 jun. 2011.

10 LERINA, Marcelo de Souza. Estimativa do peso das embalagens flexíveis. Vacaria: Central de Recebimento de Embalagens Vazias de Agrotóxicos, 2011. (Comunicação oral).

11 LIMA, C.A.B.; GRÜTZMACHER, D.D.; KRÜGER, L.R.; GRÜTZMACHER, A.D. Diagnóstico da exposição ocupacional a agrotóxicos na principal região produtora de pêssego para indústria do Brasil. Ciência Rural, v.39, p.900-903, 2009.

12 PINTO JUNIOR, A.G.; BRAGA, A.M.C.B. Trabalho e saúde: a atividade da queima de resíduos tóxicos em fornos de cimenteiras de Cantagalo, Rio de Janeiro. Ciência e Saúde Coletiva, v.14, p.2005-2014, 2009.

13 Prefeitura Municipal de Vacaria (PMV). Dados econômicos. Disponível em: www.vacaria.rs.gov.br Acesso em: 15 maio 2011. 